\title{
SAÚDE DE HOMENS NA PANDEMIA DA COVID-19: PANORAMA BRASILEIRO
}

\author{
MEN'S HEALTH IN THE COVID-19 PANDEMIC: \\ BRAZILIAN PANORAMA
}

\section{LA SALUD DE LOS HOMBRES EN LA PANDEMIA DEL COVID-19: PANORAMA BRASILEÑO}

\author{
Anderson Reis Sousa ${ }^{1}$ \\ Isabella Félix Meira Araújo ${ }^{2}$ \\ Cléa Conceição Leal Borges ${ }^{3}$ \\ Josias Alves de Oliveira ${ }^{4}$ \\ Márcio Soares de Almeida ${ }^{5}$ \\ Wellington Caribé \\ Fernando Jorge Nascimento Santos Junior ${ }^{7}$
}

Álvaro Pereira ${ }^{8}$

Como citar este artigo: Sousa AR, Araújo IFM, Borges CCL, Oliveira JA, Almeida MS, Caribé W, et al. Saúde de homens na pandemia da Covid-19: panorama brasileiro. Rev baiana enferm. 2021;35:e38683.

Objetivo: apresentar o panorama da saúde de homens em vivência da pandemia da Covid-19 no Brasil. Método: estudo qualitativo, realizado com 100 homens residentes no Brasil. Aplicou-se um formulário online e os dados apreendidos foram analisados pelo Discurso do Sujeito Coletivo, sustentado na Teoria da Adaptação de Enfermagem. Resultados: a pandemia da Covid-19 mobilizou as dimensões de saúde física, afetiva e sexual, familiar e conjugal, saúde no e do trabalho, financeira, social, emocional, psicológica e mental, espiritual, religiosa e bioenergética dos homens. Conclusão: repercussões deletérias, modos de adaptação para o enfrentamento e o cuidado de si dos homens compuseram o panorama da saúde no contexto pandêmico da Covid-19.

Descritores: Pandemias. COVID-19. Saúde do Homem. Masculinidade. Assistência à Saúde.

Objective: to present the health panorama of men experiencing the Covid-19pandemic in Brazil. Method: qualitative study conducted with 100 men living in Brazil. An online form was applied and the data were analyzed using Collective Subject Discourse, supported by Nursing Adaptation Theory. Results: the Covid-19 pandemic mobilized men's physical, affective and sexual, family and marital, bealth at and from work, financial, social, emotional, psychological and mental, spiritual, religious, and bioenergetic bealth dimensions. Conclusion: deleterious repercussions, coping adaptive modes, and men's self-care comprise the health panorama in the Covid-19 pandemic context.

Descriptors: Pandemics. COVID-19. Men's Health. Masculinity. Health Care.

\footnotetext{
Enfermeiro. Doutor em Enfermagem e Saúde. Professor Assistente da Escola de Enfermagem da Universidade Federal da Bahia. Salvador, Bahia, Brasil. anderson.sousa@ufba.br. https://orcid.org/0000-000।-8534-1960.

Enfermeira. Escola de Enfermagem da Universidade Federal da Bahia. Salvador, Bahia, Brasil. https://orcid.org/0000-0002-0631-994X.

Enfermeira. Mestra em Enfermagem e Saúde. Universidade Federal da Bahia. Salvador, Bahia, Brasil. http://orcid.org/0000-0002-9523-6272.

Estudante de Enfermagem. Universidade Federal da Bahia. Salvador, Bahia, Brasil. https://orcid org/ 0000-0002-51 00-5536.

Estudante de Enfermagem. Universidade Federal da Bahia. Salvador, Bahia, Brasil. https://orcid.org/0000-0002-1307-9964.

Estudante de Enfermagem. Faculdade Nobre de Feira de Santana. Feira de Santana, Bahia, Brasil. https://orcid.org/0000-0003-067। -92 I I

Estudante do Bacharelado Interdisciplinar em Saúde. Universidade Federal da Bahia. Salvador, Bahia, Brasil. https://orcid.org/0000-0003-3303-9860.

Enfermeiro. Doutor em Filosofia da Enfermagem. Professor Titular da Escola de Enfermagem da Universidade Federal da Bahia. Salvador, Bahia, Brasil. http://orcid. org/0000-0003-1615-5528
} 
Objetivo: presentar el panorama de la salud de los hombres viviendo la pandemia de Covid-19 en Brasil. Método: estudio cualitativo realizado con 100 hombres residentes en Brasil. Se aplicó un formulario en línea y los datos se analizaron mediante el Discurso del Sujeto Colectivo, basado en la Teoría de la Adaptación de Enfermería. Resultados: La pandemia de Covid-19 movilizó las dimensiones de salud física, afectiva y sexual, familiar y conyugal, de salud en y desde el trabajo, financiera, social, emocional, psicológica y mental, espiritual, religiosa y bioenergética de los hombres. Conclusión: las repercusiones deletéreas, los modos de adaptación para el enfrentamiento y el cuidado de si de los hombres compusieron el panorama de la salud en el contexto pandémico de la Covid-19.

Descriptores: Pandemias. COVID-19. Salud del Hombre. Masculinidad. Prestación de Atención de Salud.

\section{Introdução}

A pandemia da Covid-19 configura-se no maior cataclisma global do século e o principal desafio sanitário a ser superado neste tempo ${ }^{(1)}$. O Brasil é apontado como o segundo país com o maior número de casos da doença e tem vivenciado, além de impactos deletérios nas condições e nos modos de vida, comprometimentos à saúde populacional ${ }^{(2)}$. Ao analisar esse cenário preocupante sob a perspectiva relacional de sexo e gênero, especificamente das masculinidades, localiza-se marcadores específicos que revelam que as pessoas do sexo masculino têm sido mais afetadas pelo SARS-CoV- $2^{(3)}$.

Nesse cenário panorâmico, cabe destacar que, no Brasil, até o dia 29 de agosto de 2020, $56,6 \%$ dos casos confirmados e 58,2\% dos casos de óbitos eram de pessoas do sexo masculino ${ }^{(2)}$. Explicações recentes e pouco aprofundadas, ao olhar apenas para a categoria sexo, e não de gênero, têm publicizado, de maneira sexista, algumas explicações para esse cenário apresentado: fatores biológicos e cromossômicos, hormonais e imunológicos ${ }^{(3)}$.

Outros achados têm chamado atenção para o comportamento de saúde e hábitos de vida dos homens. Entretanto, um menor número de estudos tem direcionado a atenção para a relação das masculinidades, o cuidado e a situação de saúde dos homens, não somente pelo olhar sobre os aspectos clínicos e epidemiológicos da Covid-19, mas nas dimensões sociais e de saúde global; o que suscita investigações nesse âmbito $^{(4)}$. Desse modo, emerge a grande necessidade de fortalecer a produção do cuidado em Enfermagem e saúde, a fim de que intervenções coerentes, sensíveis, eficazes e resolutivas sejam implementadas e tenham como centralidade a garantia da promoção e a proteção da saúde masculina.

Ao reconhecer que a pandemia da Covid-19 tem provocado desarranjos e impactos na situação/condição de saúde das pessoas, torna-se relevante capacitar profissionais de Enfermagem e saúde para que possam intervir positivamente frente às demandas e necessidades apresentadas pelos homens, tendo em vista que a população masculina apresenta maior vulnerabilidade ao adoecimento, ao declínio no cuidado de si, à não busca, dificuldade e/ou resistência a acessar os serviços de saúde ${ }^{(5)}$.

Ao compreender as respostas adaptativas que promovem a integridade de indivíduos e grupos, mediante as bases teóricas de Enfermagem, por exemplo, é possível reconhecer como os homens têm construído e estabelecido os seus modos de adaptação ${ }^{(6)}$. Nesse sentido, este estudo foi guiado pela questão de pesquisa: Como se configura a saúde de homens em vivência da pandemia da Covid-19 no Brasil? Este artigo tem o objetivo de apresentar o panorama da saúde de homens em vivência da pandemia da Covid-19 no Brasil.

\section{Método}

Estudo qualitativo, em perspectiva sócio-histórica, no qual a linguagem é uma prática social que se alcança por meio dos processos dialógicos $^{(7)}$. Os dados apresentados neste estudo constituem um panorama de uma macropesquisa, intitulada "Vivências de homens em contexto de pandemia do novo Coronavírus-SARS-CoV-2 
Anderson Reis Sousa, Isabella Félix Meira Araújo, Cléa Conceição Leal Borges, Josias Alves de Oliveira, Márcio Soares de Almeida, Wellington Caribé, Fernando Jorge Nascimento Santos Junior, Álvaro Pereira

(Covid-19) no Brasil: um enfoque para à saúde", do qual emergiram três pesquisas subjacentes. O primeiro deles buscou analisar as atitudes e estratégias de enfrentamento à pandemia do Coronavírus-SARS-CoV-2; o segundo, a saúde mental de homens; e o terceiro, a vivência de discriminação e de estigma de homens que testaram positivo para a Covid-19 (Figura 1).

Nos três estudos participaram das pesquisas 2.170 homens: 1.015 no primeiro, 1.084 no segundo e 71 no terceiro.

Figura 1 - Layout das micropesquisas vinculadas ao projeto matriz, realizadas nas cinco regiões do Brasil

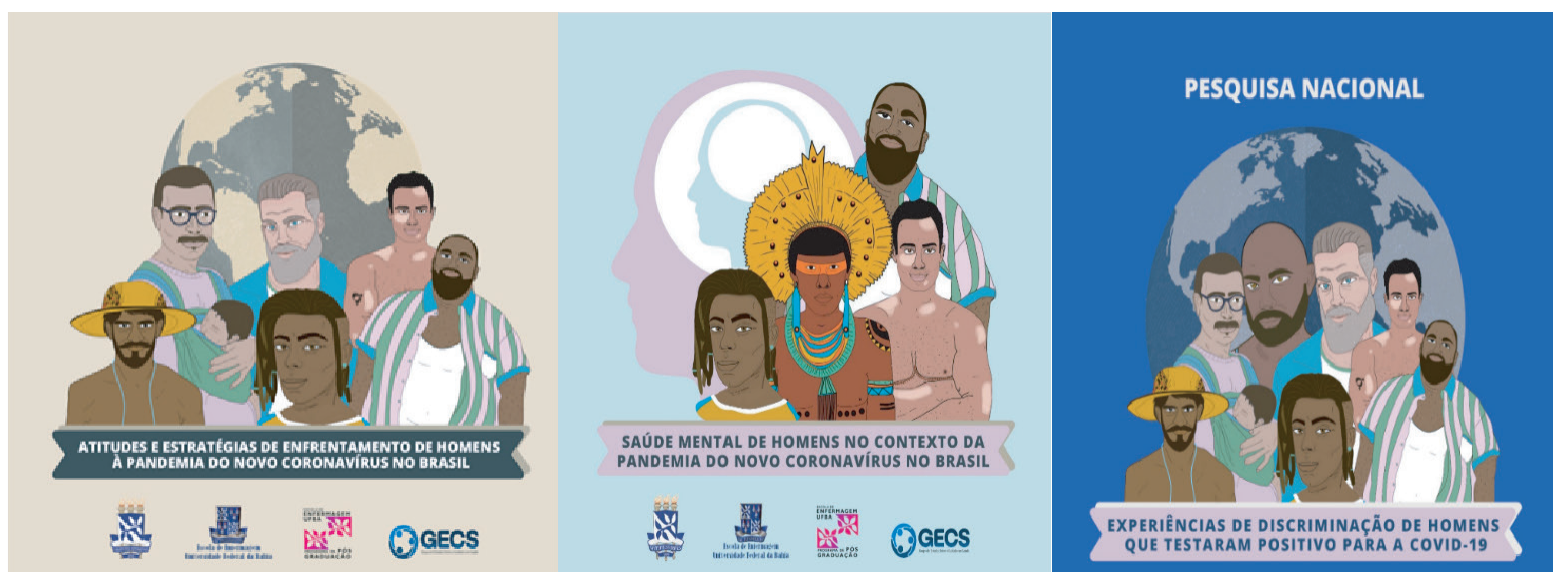

Fonte: Elaboração própria.

Os dados foram coletados entre os meses de abril e agosto de 2020 em ambiente virtual. Utilizou-se um formulário hospedado na plataforma Google Forms®. A seleção dos participantes ocorreu de maneira não sequencial e não consecutiva entre os estados brasileiros. Para acesso aos participantes realizou-se ampla divulgação do link de acesso ao formulário nas redes sociais digitais, como Facebook®, Instagram ${ }^{\circledR}$ e WhatsApp ${ }^{\circledR}$. Utilizou-se os critérios de inclusão: ser homem adulto e residente no Brasil. Não foram incluídos os homens que se encontravam em trânsito em viagem internacional no curso da pandemia e os turistas. Ademais, excluíram-se também os participantes cujos formulários estavam inconclusivos e/ou aqueles que não responderam às questões abertas. Dessa forma, para fins de análise, o material empírico de composição do corpus contou com 100 participantes, selecionados das pesquisas maiores de busca por categorias prévias de análise.

O formulário foi composto de questões fechadas e abertas. As questões fechadas versavam sobre as características sociodemográficas, econômicas e de saúde. As questões abertas tratavam das vivências dos homens no contexto da pandemia da Covid-19, a saber: Conte-nos como você tem vivenciado a pandemia da Covid-19? A pandemia da Covid-19 lhe trouxe alguma repercussão e/ou comprometimento? Fale-nos sobre a sua saúde durante a pandemia da Covid-19.

Por se tratar de um contexto sócio-histórico novo, a pandemia impulsionou a adoção de novas condutas éticas e critérios próprios de proteção dos dados, a saber: apresentação do Termo de Consentimento Livre e Esclarecido (TCLE) na modalidade imagética e a adoção de segurança digital dos dados sucedidos da ambiência virtual. O projeto foi aprovado pelo Comitê de Ética em Pesquisa, sob o Parecer número: 4.076.529, CAEE: 32889420.9.0000.5531.

Após os participantes finalizarem a pesquisa, disponibilizou-se links e contatos de acesso aos serviços de apoio e suporte psicossocial e a indicação para acesso à página do projeto no Instagram ${ }^{\circledR}$ - @ cuidadoasaudedehomens -, com o objetivo de oferecer informação, educação e 
comunicação em cuidado à saúde de homens, e também possibilitar o acompanhamento dos resultados da pesquisa.

Os dados foram analisados linha a linha, organizados e codificados. Utilizou-se o apoio do software NVIVO12 ${ }^{\circledR}$. O processamento dos dados foi realizado no software Iramutec ${ }^{\circledR}$, que permitiu expressar as palavras mais evocadas e as nuclearidades de sentido com base na árvore de similitude. Com base nessa representação, submeteu-se os dados ao método do Discurso do Sujeito Coletivo (DSC), método indutivo, que permite acessar a construção do pensamento coletivo e elucida as generalidades sobre o fenômeno investigado, bem como as Expressões Chaves, as Ideias Centrais e as Ancoragens da representação coletiva ${ }^{(8)}$. Desse modo, os dados estão apresentados em categorias de discursos-síntese. A estrutura da categorização está representada pelo infográfico construído com o suporte da ferramenta online Coggle®.

A interpretação dos dados está ancorada nos pressupostos da Teoria da Adaptação ${ }^{(6)}$, no que concerne ao conceito de saúde adotado no metaparadigma teórico, ao compreender a saúde como um processo, um estado de ser e de tornar-se inteiro, integrado, recíproco, individual e coletivamente, movido por suas respostas adaptativas. Para o cumprimento da qualidade da pesquisa qualitativa adotou-se o Consolidated Criteria for Reporting Qualitative Research (COREQ).

\section{Resultados}

Os participantes eram, em sua maioria, de identidade de gênero cisgênera, heterossexuais, raça/cor parda, com idade entre 29 e 39 anos, solteiros, com ensino superior completo e renda média acima de cinco salários mínimos.

O panorama da situação de saúde de homens residentes no Brasil no contexto da pandemia da Covid-19 revelou as dimensões da saúde contempladas no discurso masculino, estruturado no infográfico a seguir (Figura 2):

Figura 2 - Categorização dos dados: dimensões da saúde de homens no contexto da pandemia da Covid-19.

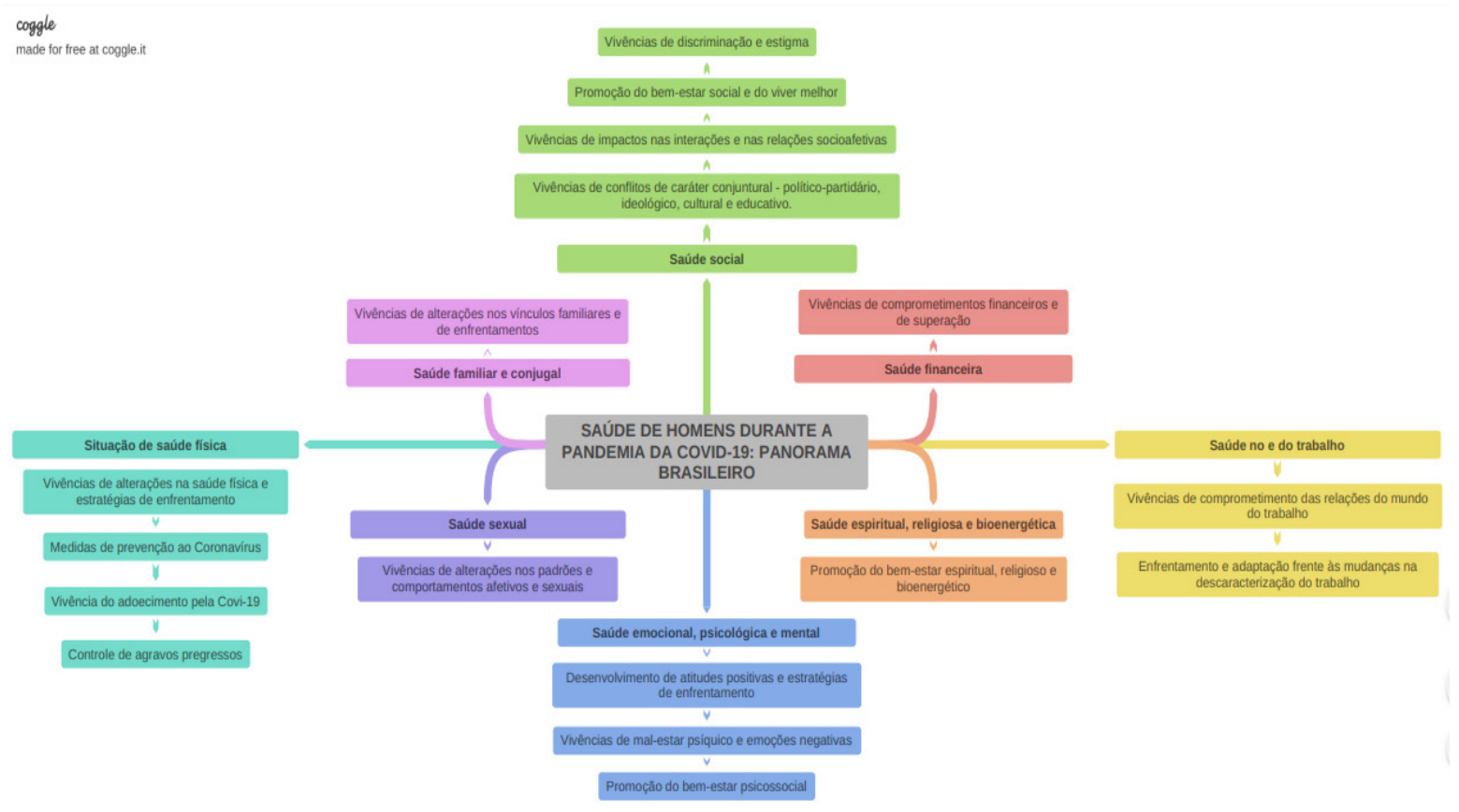

Fonte: Elaboração própria via recurso do Coogle®. 
DISCURSOS-SINTESE: DIMENSÕES DA

SAÚDE DE HOMENS NO CONTEXTO DA

PANDEMIA DA COVID-19

A categoria de discursos-sínteses está organizada em Ideias Centrais e suas subcategorias adjacentes, expostas com base nas dimensões múltiplas da saúde humana.

\section{Ideia Central 1: Situação de saúde física}

A situação de saúde física evidenciada no discurso masculino explicita o surgimento de modificações nos hábitos de vida, nas dinâmicas cotidianas, em que se destacam a alimentação, a atividade física e o consumo de conteúdos na Internet. Notou-se ainda a adoção de medidas de prevenção ao Coronavírus, o controle de agravos pregressos para a prevenção e proteção contra a Covid-19, e a vivência do adoecimento - reservada aos homens que testaram positivo para a doença -, marcada pela percepção da doença, progressividade dos sinais e sintomas, complexidade clínica da doença e deflagração de sentimentos e emoções negativas e positivas:

1A: Modos e respostas adaptativas às alterações na saúde física:

[...] com o isolamento social eu tenho dormido e me alimentado mais do que de costume. Passei a ficar mais tempo em acesso à Internet, e me exercitando menos, mas tomei consciência de que precisava me alimentar melhor, fazer uma dieta e praticar exercicios fisicos. Com os exercícios físicos eu me sinto feliz e alivia as tensões. (DSC).

1B: Modos e respostas adaptativas à prevenção ao Coronavírus:

[...] este tem sido um momento de me resguardar e adotar medidas de prevenção, tanto para mim, quanto para as demais pessoas. Busquei melhorar a minha imunidade e tentei não ficar gripado durante o período da pandemia. Fiquei mais atento com a higiene e passei a adotar hábitos diários, que vão desde a higiene pessoal até a bigiene dos alimentos e da casa. (DSC).

1C: Modos e respostas adaptativas ao controle de agravos pregressos:

[...] tenho cuidado da minha saúde física, pois eu tenho comorbidades e esta condição me coloca em situação de risco para o novo Coronavírus. Para que a situação não se agrave, eu tenho tentando manter as consultas médicas, ainda que à distância, como por telefone, já que agora durante a pandemia eu não posso ir até o serviço. Além disso, eu tenho receio de me expor e medo de con- trair a doença, o que faz com que eu permaneça mais tempo dentro de casa em isolamento social. (DSC).

1D: Modos e respostas adaptativas ao adoecimento pela Covid-19:

[...] vivi momentos de altos e baixos. Eu fui uma vítima do vírus maldito e de uma doença miserável que debilitou muito a minha saúde. Antes eu estava assintomático, mas fo $i$ evoluindo com piora e eu necessitei de internação hospitalar e depois de transferência para a Unidade de Terapia Intensiva (UTI). Eu tive alteração no olfato e no paladar, cansaço, desconfortos, dores no corpo e na cabeça, falta de ar, febre, tosse, e depois, complicações pulmonares, dispneia, pneumonia, queda na saturação, sufocamento, taquicardia. Quando eu adoeci me senti impotente, inseguro, tendo que me isolar de tudo e de todos. Durante esse periodo eu não parava de pensar em álcool em gel, casa, cautela, cloroquina, China, contágio, cuidados, cura, doença, fatalidade, IgG, intubação, leitos de UTI, máscara, morte, pandemia, prevenção, pulmão, respirador, respiração, tratamento, vacina, vírus, o que me deixava em angústia, ansiedade, apreensão, expectativa, incerteza, nervosismo, pânico, pavor, preocupação, solidão e tristeza. Depois passaram a surgir o alivio, amor, Deus, família, fé, força, paciência, saúde e superação. (DSC).

Ideia Central 2: Saúde emocional, psicológica e mental

O sujeito coletivo que fala denunciou as vivências de mal-estar psíquico e a deflagração de emoções e sentimentos negativos, que os levaram a expressar o sofrimento e a degradação da saúde emocional, psicológica e mental:

2A: Modos e respostas adaptativas ao mal-estar psíquico e às emoções negativas:

[...] os primeiros sentimentos que apareceram foram os de insegurança e incapacidade, me senti muito mal. Foram dias difíceis, não dormia bem, estava sempre cansado, com a autoestima diminuída e instável emocionalmente. Me senti ansioso, abatido, ambíguo, angustiado, aflito, apático, decepcionado, depressivo, desesperançoso, descrente, estressado, eufórico, enraivado, entediado, em luto, frustrado, instável, inseguro, melancólico, com medo, nervoso, nostálgico, em pânico, neurótico, pouco otimista, prisioneiro, solitário, sem importância, sem ser amado, surpreso, com temor da morte e muitas vezes imaginando que estava adoecendo e que estava vivendo um pesadelo. As vezes cheguei a agir com indiferença diante de tudo que estava vivendo, mas era apenas como uma forma de defesa. (DSC).

2B: Modos e respostas adaptativas para a promoção do bem-estar psicossocial:

[...] com a reflexão sobre o men estilo de vida, das minhas prioridades, eu passei a me sentir bem, em especial por buscar cuidar da minha mente, da minha vida e de quem sou eu. Tentei dar mais importância para o meu bem-estar, fazendo com que as notícias e as situaçoes ruins não me afetassem tanto. Com isso, passei a repensar os meus sentimentos e relaxar. (DSC). 
2C: Modos e respostas adaptativas para a promoção de atitudes positivas:

\begin{abstract}
[...] tem sido muita pressão muito grande sobre a minha saúde mental, mas eu tenho tentado olhar para o futuro com esperança e otimismo, buscando ter calma, paciência, me superar a cada dia esse vírus aterrorizante, sempre ver o melhor e realizar as atividades que me deixam motivado e que me façam alegre e feliz. Me senti também apaixonado neste periodo de quarentena, em especial por mim mesmo. A pandemia também me trouxe a oportunidade de evoluir enquanto pessoa e me fazer ser mais atuante e influente para a sociedade, além de ter me feito exercitar mais a coragem para enfrentar os desafios do dia dia e a enxergar melhor o futuro, alimentando as minhas esperanças. (DSC).
\end{abstract}

\section{Ideia Central 3: Saúde familiar e conjugal}

3A: Modos e respostas adaptativas às alterações nos vínculos familiares:

[...] tenho muita preocupação com os meus pais e familiares, pois muitos já são idosos e outros possuem doenças crônicas e por essas razões fazem parte do grupo de risco, e eu temo que eles possam se contaminar. Com a pandemia eu necessitei me afastar da família pois tinha medo de transmitir o vírus para eles, mas mesmo com tudo isso eu busquei aproveitar mais os meus familiares, tentei estar próximo através de ligações, chamadas de vídeos $e$ passei a dar mais atenção aos mesmos. Em relação a vida conjugal eu passei a vivenciar mais conflito do que antes, mas tenho tentado controlar o estresse, manter a calma, a paciência e buscar resolver os desentendimentos de forma amigável. (DSC).

\section{Ideia Central 4: Saúde sexual}

4A: Modos e respostas adaptativas às alterações nos padrões/comportamentos afetivos e sexuais:

[...] a pandemia acabou provocando mudanças nos meus sentimentos, senti uma necessidade maior de transar, pelo menos mais de uma vez por dia, mas em outros momentos a ausência total desta vontade. Meus relacionamentos sexuais foram prejudicados pois não tive como manter os encontros e as saídas como antes. (DSC).

\section{Ideia Central 5: Saúde no e do trabalho}

5A: Modos e respostas adaptativas ao comprometimento das relações com o trabalho:

[...] o fato de presenciar as flexibilizações trabalbistas, a redução de gastos públicos para o enfrentamento da pandemia também afetaram a minha saúde, pois me causavam pavor. Tenho receio de sair para ir trabalhar pois tenbo medo de me contaminar, e no trajeto até o trabalho e até mesmo no ambiente em que eu atuo, não bá nenhuma proteção. Em grande parte me sinto pressionado e sobrecarregado, em alguns momentos até exausto em ter que manter a produtividade do trabalho e a intelectual durante esse período. Tem sido difícil manter a produtividade durante este período da pandemia, e me sentido pressionado. Há também um impacto no cumprimento das minhas obrigações acadêmicas, pois estou desmotivado. (DSC).

5B: Modos e respostas adaptativas às mudanças na descaracterização do trabalho:

[...] mesmo com todas as transformações que tive com o trabalho, uma vez que tive que me readaptar e ter que trabalhar em casa, com o trabalho home office, eu tenho tentado manter uma rotina de trabalho, pois temo ser demitido, e também pelo fato de que é importante trabalhar. (DSC).

\section{Ideia Central 6: Saúde financeira}

6A: Modos e respostas adaptativas ao comprometimento das finanças:

[...] devido ao isolamento social eu tive muitos problemas para equilibrar as finanças. Sofri impactos com o trabalbo e os gastos aumentaram muito. Os preços, como os de alimentos no supermercado, ficaram muito altos. Tem sido difícil manter a questão financeira, mas eu tenbo tentado controlar os gastos, comprar apenas o essencial, evitar desperdicios e a rever posições profissionais, projeto de carreira e atribuições acadêmicas, pois eu não tenho boas perspectivas do futuro em relação à economia. (DSC).

\section{Ideia Central 7: Saúde social}

7A: Modos e respostas adaptativas aos conflitos conjunturais - político-partidário, ideológico, cultural e educativo:

[...] acabei vivenciando situações que me deixaram na contramão do que seria ideal a ser cumprido durante uma pandemia, pois presenciei políticos acusando uns aos outros, autoridades acusando os países pela responsabilidade do surgimento e avanço da doença, como ocorrido com a China. Todas essas situações comprometeram as minhas decisões durante esse periodo, me fizeram ter descrença no meio político, que além de não cumprir com o seu papel, se direciona para o lado oposto do correto a ser feito em uma pandemia, se aproveitando do momento para cometer atos de corrupção e roubo $e$ tornando mais vulnerável ainda a minha situação de saúde, uma vez que não garante o cuidado e a segurança necessária. Além disso, passei a sentir muita raiva e envergonhado pelo desgoverno de Bolsonaro e frustração com o Brasil. (DSC).

7B: Modos e respostas adaptativas aos impactos nas interações/relações socioafetivas:

[...] o isolamento social me provocou muita solidão. A minha relação com as pessoas mais próximas e os amigos foram totalmente afetadas. Passei a sentir a falta de ver as pessoas e muita saudade, pois a frequência de contato bumano que eu tinha antes da pandemia mudou completamente. Tem sido uma sensação crescente de inseguranç, principalmente pela incerteza de não saber como seria o futuro e o retorno na convivência normal que havia antes. (DSC). 
Anderson Reis Sousa, Isabella Félix Meira Araújo, Cléa Conceição Leal Borges, Josias Alves de Oliveira, Márcio Soares de Almeida, Wellington Caribé, Fernando Jorge Nascimento Santos Junior, Álvaro Pereira

7C: Modos e respostas adaptativas à discriminação e ao estigma:

[...] eu sofri discriminação, preconceito e estigma após saberem que eu estava com a doença. Amigos, conbecidos, familiares e colegas de trabalbo se distanciaram. Alguns até deixaram de falar comigo e outros passaram a fingir que não me conbeciam. Fui chamado pelo nome da doença, inclusive por profissionais de saúde e tudo isso abalou o meu psicológico e influenciou de maneira negativa a minha recuperação. (DSC)

7D: Modos e respostas adaptativas para a promoção do bem-estar social e do viver melhor:

[...] não tem sido fácil ficar muito tempo dentro de casa, isolado, sem poder estar envolvido com as rotinas do dia a dia, no contato com os colegas de trabalho, família, e pessoas com quem eu me relaciono afetivamente, geram momentos de apreensão. Tenho buscado realinhar as relações. (DSC).

Ideia Central 8: Saúde espiritual, religiosa e bioenergética

8A: Modos e respostas adaptativas para a promoção do bem-estar espiritual, religioso e bioenergético:
[...] tenho buscado tomar consciência, ir em busca da paz, do contentamento e o encontro comigo mesmo e de ter a sensação de vida. Tem sido um momento de recolbimento e reflexão, principalmente espiritual, reservando as minhas energias, e evitando as trocas negativas que são trazidas pela pandemia. Busco estar olbar mais para dentro de mim, estar em equilíbrio, refletir sobre a minha posição social e o meu valor para o próximo e para o mundo e estar aberto para um novo recomeço de vida, como novos aprendizados, reivenções e descobertas. Além disso busquei ter fé, não nos governantes, mas em Deus e na nação. Eu glorifico a Deus a cada dia por estar vivo, por não estar doente e assim busco me alegrar nisto. (DSC).

O panorama da saúde de homens no contexto da pandemia da Covid-19 no Brasil encontra-se evidenciado na Árvore de Similitude (Figura 3). Nota-se quatro ramificações de configuração mais salientes e com conexões existentes entre os seus ramos. Ao centro, "sentir", em mobilização por "passar" e "pandemia", que se conecta junto à outras ramificações, representadas pelo "até" e "como".

Figura 3 - Árvore de Similitude acerca da saúde de homens no contexto da pandemia da Covid-19 no Brasil.

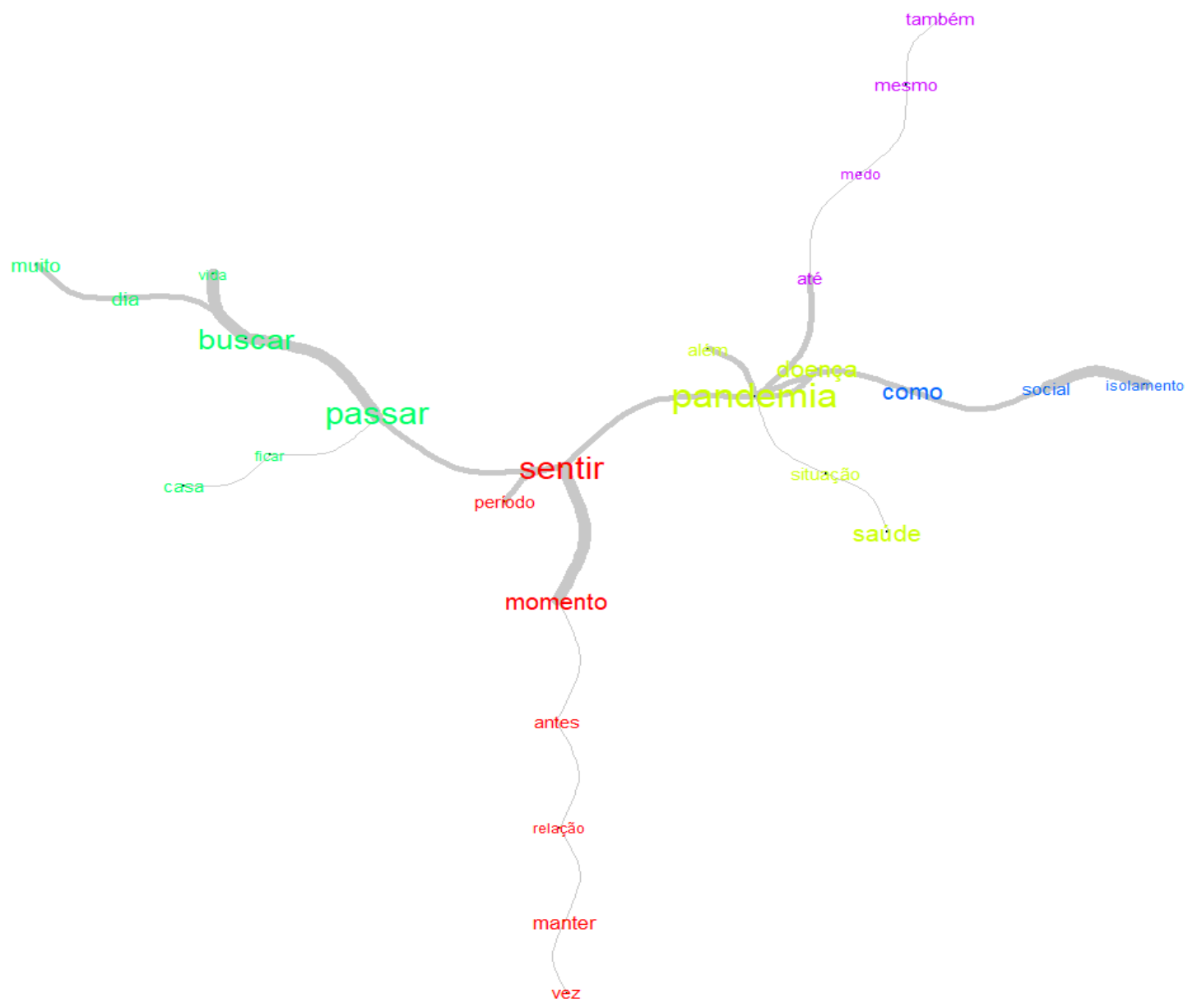




\section{Discussão}

Os achados deste estudo são capazes de revelar o panorama da saúde de homens residentes no Brasil no contexto da pandemia da Covid-19 e explicitar as distintas dimensões da saúde masculina manifestadas nos discursos coletivos, o que permite vislumbrar a magnitude das repercussões e das adaptações ${ }^{(6)}$ no curso pandêmico.

Quando analisadas as dimensões de saúde física, mesmo que se configure uma medida eficaz para o controle e disseminação do vírus, o isolamento social pode trazer impactos e consequências deletérias, como o aumento do sedentarismo e a falta de atividade física. Além disso, passar maior tempo dentro de casa, propicia menos interação social e consequente maior utilização de equipamentos eletrônicos, como computadores, aparelho celular e uso de TV, o que pode provocar maior tempo de inatividade sentado e/ou deitado $^{(9)}$. Salienta-se que fatores internos e externos podem se configurar em estímulos aos sistemas de adaptação, comprometendo as capacidades para o enfrentamento, e por esta razão deve ser melhor investigado ${ }^{(6)}$.

A literatura tem apontado que os homens, comparados às mulheres, apresentaram maior prevalência de fatores de risco, como o tabagismo, sobrepeso e o consumo abusivo de bebidas alcoólicas. Além de torná-los mais vulneráveis à infecção pelo SARS-CoV-2 ${ }^{(3)}$, tais problemáticas podem se intensificar durante o confinamento imposto pelo avanço da Covid-19. Além disso, a mortalidade relacionada ao risco cardiovascular tem sido mais elevada entre o público masculino ${ }^{(10)}$. Nesse sentido, uma atenção focada deve ser dispensada pelos profissionais de Enfermagem e saúde, a fim de empregar estratégias de enfrentamento eficazes, a exemplo do que tem sido divulgado na produção científica no contexto pandêmico, ao destacar os exergames como estratégia eficaz de promoção das práticas corporais no período de isolamento ${ }^{(11)}$.

Os achados demonstraram que parte dos homens vivenciaram o adoecimento por Covid-19, o que confirma a sua veracidade e impactos, e o temor, sobretudo por aqueles homens que se encontravam no "grupo chave" para a nova doença, e houve a tentativa de se localizar o ambiente adaptativo em que esses homens crescem, modificam, desenvolvem e florescem ${ }^{(6)}$.

No âmbito da saúde mental dos homens, a pandemia ocasionou repercussões negativas, seja pela elevação da ansiedade, do estresse, o isolamento social, seja pelo medo da infecção, da morte, do luto complexo e aproximado, do medo de perder algum algum ente querido, ou mesmo pela massiva veiculação de notícias vinculadas sobre os efeitos da pandemia. Entretanto, no âmago de estratégias de enfrentamento para o momento atípico, pemite-se visualizar aspectos positivos, como a possibiliade de ficar mais tempo junto à família, refletir sobre novos hábitos de melhoria de vida e novas rotinas que possibilitam satisfação interior. Da mesma forma, compreender que outras pessoas tambem estão sofrendo em decorrência do novo Coronavírus diminui a sensação de fracasso e/ou solidão, aspectos que devem ser melhor explorados entre a população masculina ${ }^{(12)}$.

O estudo demonstra que o contexto da pandemia impactou negativamente a saúde mental dos homens de maneira (inter)subjetiva, dimensão que Calista Roy compreende como sistemas adaptativos ${ }^{(6)}$, o que pode ser decorrência da insegurança, do medo e da incapacidade de enfrentamento do fenômeno. Esse ambiente instável gerou nos homens um mal-estar, cujos sentimentos expressados demonstraram sofrimento psíquico. A literatura sobre o tema tem revelado mudanças de humor masculino expressivo, sintomatologia depressiva e ansiosa durante a pandemia, mas contraria os estudos com a população geral, que apontam cenário menos favorável para as mulheres ${ }^{(13)}$. Outra marca relevante deste estudo diz respeito ao fato de que os homens explicitaram a saúde mental como uma dimensão da saúde de notória importância entre as vivências masculinas, em especial, pelo encobrimento desse lugar na saúde global. Outro avanço deu-se com a superação das adversidades e o emprego de práticas adaptativas em promoção do bem-estar psicossocial, como a 
Anderson Reis Sousa, Isabella Félix Meira Araújo, Cléa Conceição Leal Borges, Josias Alves de Oliveira, Márcio Soares de Almeida, Wellington Caribé, Fernando Jorge Nascimento Santos Junior, Álvaro Pereira

autocompaixão, a resiliência e a ressignificação da vida ${ }^{(14-15)}$.

Em convergência com esse panorama, algumas relações foram distanciadas por conta das medidas de isolamento social, obrigando diversas famílias a manterem-se afastadas, o que provoca angústias, potencializa as incertezas, as distâncias dos entes queridos e têm gerado o comprometimento emocional masculino ${ }^{(15-18)}$. A vinculação familiar e a saúde da família foi manifestada pelos homens, o que advém do reflexo da degradação familiar e da sensação de impotência face as retrições e limitações na integração com as redes socioafetivas/familiares ${ }^{(17,19)}$. A família pode configurar-se um sistema adaptativo e permitir que o indivíduo se adapte de maneira integrada, compensatória ou comprometida ${ }^{(6)}$; o que propicia que a adaptação masculina em contextos de pandemia seja reconhecida por profissionais de Enfermagem e saúde. Desse modo, potencializar o cuidado de família no âmbito das intervenções estratégias, contingenciais e programáticas de Enfermagem se fazem indispensáveis no contexto pandêmico, como forma de minimizar os impactos na saúde familiar e também conjugal dos homens, dado que evidências já sinalizam as contribuições da familia para o fortalecimento da resiliência ${ }^{(15)}$.

Outrossim, ao vivenciarem o prolongamento da pandemia em conjunto com suas consortes e/ ou cônjuges, os homens podem estar vivenciando alterações emocionais emergentes. Elevação do estresse, conflitos interpessoais e falta de privacidade podem tornar o cenário mais propício para as violências e elevação dos danos psicológicos, morais, patrimoniais, físicos, sexuais e de outra natureza, provocados por tal contexto ${ }^{(15)}$. Desse modo, é relevante a tomada de conduta conjunta de gestores, profissionais de Enfermagem e saúde e da rede de prevenção e enfrentamento para a superação dos impactos degradantes causados à saúde conjugal e comunitária.

A saúde sexual foi destacada como uma dimensão da saúde masculina impactada pela pandemia. Com o afastamentos dos corpos e do contato físico aproximado, repercussões inesperadas comprometeram as práticas sexuais masculinas.
A ausência da adaptação integrada, quando estruturas e funções estão ausentes, como está ocorrendo com a interrupção das relações sexuais, compromete as necessidades humanas ${ }^{(6)}$. Permeadas por perspectivas relacionais de gênero e masculinidades, as relações sexuais contribuem para a promoção da autoestima e do bem-estar geral e psicológico. As mudanças nos padrões de comportamentos sexuais - alteração na frequência, libido, qualidade da relação sexual, afetividade, parceria ou relacionamento sexual solo - têm implicado em impactos diretos na saúde mental e necessitam ser levadas em consideração durante esse contexto ${ }^{(16)}$.

Intercalados com os aspectos da saúde sexual, quando associadas às oscilações emocionais por conta de medo, ansiedade, preocupação e solidão, reflexos fisiológicos e comportamentais podem comprometer ainda mais a dimensão das sexualidades. O abandono das medidas de proteção no sexo durante a pandemia, a não adesão a métodos de barreira, como o uso de preservativos, o desinteresse pelo sexo, ainda que virtual, e o comprometimento no estabelecimento de relações afetivas de caráter sexual são observados na literatura ${ }^{(17)}$.

Ainda sobre esse aspecto, na tentativa de traçar estratégias de enfrentamento, algumas ações institucionais e advindas dos movimentos sociais estão buscando orientar e apoiar a população para a adaptação às novas práticas sexuais durante a pandemia. Para isso, estão sendo promovidos, por exemplo, o estímulo à adoção de práticas do sexting, quarentine, remote threesomes e sext bunker, sexo virtual e uso de aplicativos de geolocalização para encontros sexuais online. Além disso, é importante refletir que motéis, clubes de sexo, saunas e outros pontos para encontros sexuais foram quase que totalmente fechados, o que dificultou as práticas sexuais, e por essas razões, devem ser consideradas ${ }^{(18-19)}$.

Ao direcionar atenção para a saúde social, o discurso dos homens revelou as vivências de repercussões de caráter estrutural, de ligação política, negacionista, o que tem comprometido a população a alcançar direitos, ter acesso a informações seguras e adotar as medidas de 
prevenção e controle da doença indicadas ${ }^{(20)}$. Para os homens que vivenciam a experiência da enfermidade, o surgimento da discriminação e do estigma tornou a saúde masculina ainda mais afetada, especialmente pela sobreposição de barreiras a serem enfrentadas ${ }^{(21)}$.

No que concerne às dimensões da saúde do e no trabalho, assim como à saúde financeira da população masculina face a vivência da pandemia da Covid-19 no Brasil, é imprescindível considerar que, no cenário brasileiro, a função social do trabalho foi severamente alterada. A problemática tem sido mais impactante para o grupo de homens que convivem com vinculações precárias de trabalho, os que são autônomos, sem renda fixa e aqueles que lidam cotidianamente com a instabilidade salarial. Soma-se ainda o fato de que, por conta do isolamento social requerido, muitos homens perderam o contato com os ambientes e colegas de trabalho e/ou pessoas com quem interagia ao realizar suas atividades e ainda estão comprometidos pelo grave prejuízo financeiro e a crise econômica. Dessa maneira, para compensar adaptativamente esse cenário, o indivíduo necessita valer-se de recursos cognitivos-reguladores ou estabilizadores-inovadores, para superar o problema vivenciado ${ }^{(6)}$.

Importante destacar que, ao vivênciar impactos na saúde no/do trabalho e financeira, os homens podem estar mais vulneráveis à exposição e à disseminação do Coronavírus, por estarem mantendo as suas atividades laborais mesmo com a pandemia em curso ${ }^{(20)}$. Soma-se ainda o fato de estarem convivendo com condições de trabalho precárias, sobrecarga, descaracterização das relações do trabalho, aumento de novas demandas com o teletrabalho e o bome office, desemprego, perdas salariais, dificuldade de acesso ao auxílio emergencial, além de estarem mais susceptíveis ao sofrimento psíquico no trabalho e a desenvolverem transtornos ansiogênicos, depressivos e o suicídio. Dessa forma, urge a necessidade de fortalecer as iniciativas de apoio organizacional e as políticas de promoção do bem-estar e proteção no/do trabalho.

A dimensão da saúde espiritual, religiosa e bioenergética emergiu no discurso coletivo e pode ter se manifestado devido ao recolhimento repentino, que se mostra desafiador no contexto da autopreservação, contribuindo para que busquem a espiritualidade, a crença e a fé, importantes aliadas na manutenção do equilíbrio mental e espiritual dos homens na pandemia ${ }^{(22)}$. Atitudes e sentimentos positivos, como o amor, a esperança e a fé, bem como a produção de sentidos, significados e propósitos na vida das pessoas, podem ampliar-se, o que contribui para o enfrentamento e a elevação dos campos energéticos e vibracionais ${ }^{(23)}$. Destarte, a prática religiosa tem se mostrado eficaz no auxílio à redução da ansiedade, aporta valor satisfatório à noção de existência e pode promover a alegria $^{(22)}$. É relevante ressaltar que a saúde emerge como um reflexo de interações pessoais e ambientais que são adaptativas ${ }^{(6)}$, que se encontram em íntima convergência com o existencialismo, com o humanismo existente na dimensão espiritual, religiosa e bioenergética. Desse modo, a produção do cuidado de Enfermagem necessita explorar, valorizar, estimular o emprego de práticas de cuidado à saúde nessa dimensão.

As contribuições deste estudo estão direcionadas ao avanço no conhecimento e na prática de Enfermagem no tocante à produção do cuidado no contexto pandêmico face ao advento de uma doença infecciosa nova e as suas repercussões correlatas de caráter sociocultural, econômico, estrutural e de gênero. Aporta contributos para a clínica em Enfermagem e saúde voltada às demandas, necessidades e especificidades de saúde de homens, em interface às suas masculinidades, na medida em que revela suas atitudes, comportamentos e práticas durante o curso da pandemia da Covid-19; o que pode implicar em melhor direcionamento às intervenções e ações estratégicas, contingenciais e programáticas em saúde.

Ressalta-se ainda que este estudo, além de localizar a inedicidade do fenômeno no Brasil, mostra o seu pionerismo na América Latina e no mundo, especialmente no tocante às investigações qualitativas. Além disso, converge com as recomendações dos principais órgãos sanitários globais e brasileiros, como a Política Nacional de Atenção Integral à Saúde do Homem. Por fim, garante o avanço das validações dos pressupostos téoricos e epistemológicos de Enfermagem, na 
Anderson Reis Sousa, Isabella Félix Meira Araújo, Cléa Conceição Leal Borges, Josias Alves de Oliveira, Márcio Soares de Almeida, Wellington Caribé, Fernando Jorge Nascimento Santos Junior, Álvaro Pereira

medida em que se utiliza uma Teoria de Enfermagem para análise do fenômeno investigado.

As limitações deste estudo estão concentradas no emprego de uma única técnica de coleta dos dados, na impossibilidade de realização da coleta face a face, na elevada concentração de homens de uma determinada região do país, na seletividade conferida aos homens com maior acesso às Tecnologias da Comunicação e Informação (TIC) e ao letramento. Esses fatores impossibilitaram alcançar grupos de homens menos favorecidos, além da possibilidade de vieses existentes no acesso aos homens por meio das redes sociais utilizadas.

\section{Conclusão}

O discurso masculino evidenciou que o panorama da saúde de homens no contexto da pandemia da Covid-19 mobilizou as dimensões de saúde física, afetiva e sexual, familiar e conjugal, saúde no e do trabalho, financeira, social, emocional, psicológica e mental, espiritual, religiosa e bioenergética dos homens. Além disso, repercussões deletérias, modos de adaptação para o enfrentamento e o cuidado de si dos homens compuseram o panorama da saúde no contexto pandêmico da Covid-19.

\section{Colaborações:}

1 - concepção, projeto, análise e interpretação dos dados: Anderson Reis Sousa;

2 - redação do artigo e revisão crítica relevante do conteúdo intelectual: Isabella Félix Meira Araújo, Cléa Conceição Leal Borges, Josias Alves de Oliveira, Márcio Soares de Almeida, Wellington Caribé e Fernando Jorge Nascimento Santos Junior;

3 - aprovação final da versão a ser publicada: Álvaro Pereira.

\section{Referências}

1. Guan W, Ni Z, Hu Y, Liang W, Ou C, He J, et al. Clinical Characteristics of Coronavirus Disease 2019 in China. N Engl J Med. 2020:382:170820. DOI: $10.1056 /$ NEJMoa2002032
2. Brasil. Ministério da Saúde. Coronavírus: Boletim Epidemiológico 29. Brasília (DF); 2020 [cited 2020 Sep 1]. Available from: https://saude.gov. br/images/pdf/2020/September/02/18h-Boletimepidemiologico-COVID-29-final.pdf

3. Bwire GM. Coronavirus: Why Men are More Vulnerable to Covid-19 Than Women? SN Compr Clin Med. 2020 Jun 4;1-3. DOI: 10.1007/ s42399-020-00341-w

4. Sousa AR, Silva NSB, Lopes S, Rezende MF, Queiroz AM. Expressions of masculinity in men's health care in the context of the COVID-19 pandemic. Rev cuba enferm [Internet]. 2020 [cited 2020 Jul 10];36:e3855. Available from: http:// www.revenfermeria.sld.cu/index.php/enf/article/ view/3855/608

5. Sousa AR, Queiroz AM, Florentino RMS, Portela PP, Fernandes JD, Pereira A. Homens nos serviços de Atenção Básica à Saúde: repercussões da construção social das masculinidades. Rev baiana enferm. 2016;30(3):1-10. DOI: 10.18471/ rbe.v30i3.16054

6. Roy C. El modelo de adaptación de Roy en el contexto de los modelos de enfermería, con ejemplos de aplicación y dificultades. Cult cuid. 2000;4(7-8):139-59. DOI: 10.14198/cuid.2000.7-8.17

7. Freitas MTA. A abordagem sócio-histórica como orientadora da pesquisa qualitativa. Cad Pesqui. 2002;(116):21-39. DOI: 10.1590/ S0100-15742002000200002

8. Lefevre F, Lefevre AMC. Discurso do sujeito coletivo: representações sociais e intervenções comunicativas. Texto contexto - enferm. 2014;23(2):502-7. DOI: 10.1590/0104-07072014000000014

9. Souza Filho BAB, Trintany ÉF. COVID-19: importância das novas tecnologias para a prática de atividades físicas como estratégia de saúde pública. Cad Saúde Pública. 2020;36(5):e00054420. DOI: $10.1590 / 0102-311 \times 00054420$

10. Mussi FC, Teixeira JRB. Fatores de risco cardiovascular, doenças isquêmicas do coração e masculinidade. Rev cuba enferm [Internet]. 2018 [cited 2020 Sep 1];34(2). Available from: http:// www.revenfermeria.sld.cu/index.php/enf/article/ view/1613

11. Viana RB, Lira CAB. Exergames as Coping Strategies for Anxiety Disorders During the COVID-19 Quarantine Period. Games Health J. 2020;9(3):147-9. DOI: 10.1089/g4h.2020.0060 
12. Zanon C, Dellazzana-Zanon LL, Wechsler SM, Fabretti RR, Rocha KN. COVID-19: implicações e aplicações da Psicologia Positiva em tempos de pandemia. Estud Psicol (Campinas). 2020;37(2):e200072. DOI: https://dx.doi.org/10. 1590/1982-0275202037e200072

13. Kong $\mathrm{X}$, Zheng $\mathrm{K}$, Tang $\mathrm{M}$, Kong $\mathrm{F}$, Zhou J, Diao L, et al. Prevalence and Factors Associated with Depression and Anxiety of Hospitalized Patients with COVID-19. MedRxiv. 2020. DOI:10.1 101/2020.03.24.20043075

14. Duarte MQ, Santo MAS, Lima CP, Giordani JP, Trentini CM. COVID-19 e os impactos na saúde mental: uma amostra do Rio Grande do Sul, Brasil. Ciênc saúde coletiva. 2020;25(9):3401-11. DOI: doi.org/10.1590/1413-81232020259.16472020

15. Moretti SA, Guedes-Neta ML, Batista EC. Nossas Vidas em Meio à Pandemia da COVID-19: Incertezas e Medos Sociais. Rev Enfermagem e Saúde Coletiva [Internet]. 2020 [cited 2020 Aug 20];4(2):32-41. Available from: https://www.revesc. org/index.php/revesc/article/view/57/66

16. Prime H, Wade M, Browne DT. Risk and resilience in family well-being during the COVID-19 pandemic. Am Psychol. 2020;75(5):631-43. DOI: 10.1037/amp0000660

17. Ibarra FP, Mehrad M, Mauro MD, Godoy MFP, Cruz EG, Nilforoushzadeh MA, et al. Impacto da pandemia COVID-19 no comportamento sexual da população. A visão do leste e do oeste. Int braz j urol. 2020;46(Suppl 1):104-12. DOI: https://doi. org/10.1590/s1677-5538.ibju.2020.s116
18. Sin J. Sex in self-isolation: Four ways to quench your pandemic thirst [Internet]. Toronto: NOW; 2020 [cited 2020 Aug 15]. Available from: https://nowtoronto.com/lifestyle/sex-selfisolation-teledildonics-erotica

19. NYC Health. Safer Sex and COVID-19 [Internet]. Nova York (US); 2020 [cited 2020 Aug 15]. Available from: https://www1.nyc.gov/assets/doh/ downloads/pdf/imm/covid-sex-guidance.pdf

20. Cruz RM, Borges-Andrade JE, Moscon DCB, Micheletto MRD, Esteves GGL, Delben PB, et al. COVID-19: emergência e impactos na saúde e no trabalho. Rev Psicol Organ Trab. 2020;20(2):I-III. DOI: http://dx.doi.org/10.17652/ rpot/2020.2.editorial

21. Bagcchi S. Stigma during the COVID-19 pandemic. Lancet Infect Dis. 2020;20(7):782. DOI: 10.1016/S1473-3099(20)30498-9

22. Reis LA, Menezes TMO. Religiosity and spirituality as resilience strategies among long-living older adults in their daily lives. Rev Bras Enferm. 2017;70(4):761-6. DOI: http://dx.doi. org/10.1590/0034-7167-2016-0630

23. Roman NV, Mthembu TG, Hoosen M. Spiritual care - 'A deeper immunity' - A response to Covid-19 pandemic. Afr J Prim Health Care Fam Med. 2020;12(1):e1-e3. DOI: 10.4102/phcfm.v12i1.2456

Recebido: 4 de setembro de 2020

Aprovado: 29 de setembro de 2020

Publicado: 8 de junho de 2021

A Revista Baiana de Enfermagem utiliza a Licença Creative Commons - Atribuição-NãoComercial 4.0 Internacional.

https://creativecommons.org/licenses/by-nc/4.0/

Este artigo é de acesso aberto distribuído sob os termos da Licença Creative Commons (CC BY-NC).

Esta licença permite que outros remixem, adaptem e criem a partir do seu trabalho para fins não comerciais. Embora os novos trabalhos tenham de lhe atribuir o devido crédito e não possam ser usados para fins comerciais, os usuários não têm de licenciar esses trabalhos derivados sob os mesmos termos. 